\title{
ESTUDIO MULTICÉNTRICO EUROPEO PARA LA PREVENCIÓN DE LA ENDOFTALMITIS EN LA CIRUGÍA DE LA CATARATA
}

\section{THE ESCRS STUDY ON ANTIBIOTIC PROPHYLAXIS FOR ENDOPHTHALMITIS FOLLOWING CATARACT SURGERY}

\author{
ABREU JA ${ }^{1}$, ALIÓ JL ${ }^{1}$, CORDOVÉS LM ${ }^{1}$, FERRER C ${ }^{1}$
}

La cirugía de la catarata es en la actualidad la intervención quirúrgica más frecuente en los países desarrollados. La infección intraocular consecutiva a esta operación, la endoftalmitis, puede tener consecuencias tan devastadoras como la ceguera. La frecuente práctica de la operación de catarata, convierte a la misma en la primera causa de endoftalmitis, con gravísimas consecuencias clínicas, elevando costo sanitario y, además, frecuente causa de litigación médico-legal (1). Hasta ahora no existían estudios científicos válidos que demostrasen que la profilaxis antibiótica reduzca el riesgo de contraer una endoftalmitis tras la cirugía de la catarata. La única medida universalmente aceptada era el empleo de la povidona iodada (PI) como antiséptico preoperatorio (2).

La incidencia de endoftalmitis tras la cirugía de la catarata sufrió un descenso progresivo en la medida que fueron mejorando la técnica y condiciones quirúrgicas. En los últimos años su incidencia se ha incrementado, atribuyéndose este hecho al empleo de la incisión por córnea clara y sin suturas La incidencia actual referida en series retrospectivas oscila entre un 0,015 y $0,5 \%$ (3).

El problema se plantea desde la perspectiva de cuál es la profilaxis antibiótica a utilizar. La utilización indiscriminada de antibióticos de uso restringido tales como la vancomicina, con el riesgo de aparición de resistencias bacterianas y de toxicidad ocular en relación con errores de dilución, es objeto de continua controversia.

Hasta la fecha, no existía una pauta antibiótica definida como «adecuada», en base a un suficiente soporte científico, lo cual ha conllevado a innume- rables contradicciones y recomendaciones de mucho o escaso fundamento. Todo esto, junto con las implicaciones médico-legales derivadas, motivó que la Sociedad Europea de Cirujanos de Catarata y Refractiva (ESCRS) considerase la necesidad en su congreso anual, celebrado en 1995 en Amsterdam, de realizar un estudio a nivel de la Unión Europea, que definiera en base a la evidencia científica cuál es la más adecuada profilaxis antibiótica de la endoftalmitis tras la cirugía de la catarata. Dicho estudio (ESCRS Endoftalmitis Study) se inició, tras diferentes vicisitudes, en septiembre del año 2003. En enero del presente año, el comité de seguimiento del estudio, decidió interrumpirlo al haberse alcanzado los niveles de significación estadística prefijados y confirma que una de las pautas seguidas en uno de los grupos del estudio era claramente superior a los demás. En este estudio han participado veinticuatro hospitales de nueve países de la UE. España ha estado representada por cuatro centros pertenecientes dos a la Comunidad de Canarias (Hospital Universitario de Canarias-Tenerife y Hospital Universitario Virgen de la Candelaria-Tenerife), uno a la Comunidad de Madrid (Hospital Oftalmológico Internacional, VISSUM-Madrid), y uno a la Comunidad Valenciana (Instituto Oftalmológico de Alicante, VISSUM-Alicante). En el estudio se usaron dos centros de referencia a los que se enviaban las muestras desde los hospitales participantes para la realización de la Reacción en Cadena de la Polimerasa (PCR), uno en Alemania y otro en España (Instituto Oftalmológico de Alicante, VISSUMAlicante).

\footnotetext{
1 Doctor en Medicina.

E-mail: jabreu@oftalnet.nu / jlalio@vissum.com
} 
Este ensayo multicéntrico, prospectivo, consecutivo, aleatorizado y controlado, reclutó más de 16.000 pacientes, de los cuales 15.971 completaron el estudio. Las variables a estudiar fueron el empleo perioperatorio de colirio de levofloxacino (1 gota 1 hora y $1 / 2$ hora antes de la cirugía, 3 gotas con intervalos de 5 minutos justo al acabar la cirugía) y la inyección de $1 \mathrm{mg}$ de cefuroxima en cámara anterior justo al final de la intervención. Los pacientes fueron agrupados de forma aleatoria en cuatro grupos con un diseño factorial $2 \times 2$, tal y como se puede ver en la tabla de resultados (fig. 1). Todos los grupos tenían en común el uso prequirúrgico de PI $5 \%$ y postquirúrgico (a partir del primer día postoperatorio) de colirio de levofloxacino $0,5 \%$ cada 6 horas durante 6 días.

Analizando los resultados se observa que el grupo en el que se usó la inyección de cefuroxima en cámara anterior al final de la cirugía consigue una disminución muy importante de la incidencia de endoftalmitis (Odds Ratio 4.8, $\mathrm{p}=0.002$ para las diagnosticadas clinicamente; Odds Ratio 5.6, $\mathrm{p}=0,006$ para las probadas) mientras que el empleo de colirio de levofloxacino perioperatoriamente no consigue una reducción estadísticamente significativa de la frecuencia y riesgo de padecer una endoftalmitis tras la cirugía de catarata.

Los resultados del estudio realizado por la ESCRS son clínicamente altamente significativos. Del mismo se deduce inequívocamente que la

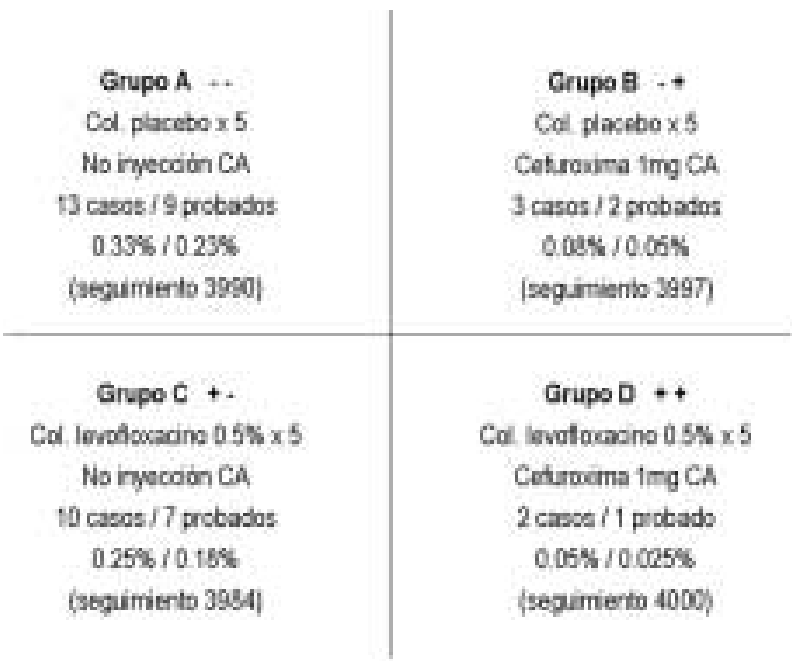

Fig. 1: Muestra los grupos y sus características, así como el número y porcentaje de casos de endoftalmitis; totales (diagnosticadas por la clínica) y probadas (confirmadas por cultivos y/o PCR). mejor manera de prevenir la infección tras la cirugía de la catarata es el uso preoperatorio de povidona iodada al 5\% para limpieza de piel y superficie del globo ocular asociada a la inyección de cefuroxima ( $1 \mathrm{mg} / 0,1 \mathrm{ml})$ en CA al final de la cirugía (3), lográndose así una incidencia entre $0,06 \%$ (endoftalmitis totales) y $0,04 \%$ (endoftalmitis probadas).

Del estudio también se deducen otras conclusiones entre las que destaca el mayor índice de endoftalmitis cuando se utilizan lentes intraoculares de silicona respecto a las acrílicas ( 3,3 veces mayor en el número total de endoftalmitis y 4,5 en el número de probadas, $\mathrm{p}=0,002)$ (4).

La cefuroxima sigue sin estar autorizada ni disponible en una presentación comercial para uso intraocular, pero se puede solicitar su uso compasivo a través de los servicios de farmacia hospitalaria, aportando como apoyo documental a dicha solicitud las publicaciones de la ESCRS. Estos servicios también nos pueden facilitar la cefuroxima en las condiciones y concentración adecuada para su uso intraocular según las recomendaciones del estudio, evitando los riesgos de la denominada por la literatura anglosajona «farmacia casera» o «kitchen pharmacy».

El disponer de un modelo probado de profilaxis antibiótica capaz de disminuir la incidencia de las endoftalmitis a 4 por 10.000 cirugías, utilizando un antibiótico genérico y barato como la cefuroxima, dejando las otras familias de antibióticos para el tratamiento, es sin duda uno de los logros con mayor repercusión clínico-económica en la actual cirugía de la catarata, y que sin duda alguna implicará al resto de la cirugía del segmento anterior. Si asumimos que en España se operaron 200.000 cataratas en el año 2005, la profilaxis realizada con cefuroxima preparada en la farmacia hospitalaria a partir de la presentación genérica de la misma hubiera tenido un coste aproximado de 9.360 euros.

¿Estamos obligados a asumir los resultados del estudio de la ESCRS? Por un lado está el «deber de actualización» para dar a nuestros pacientes la mejor atención posible, la «lex artis», aunque en España no se contempla legalmente un tiempo concreto para asumir las novedades científicas. Por otro lado está el que se trata de un fármaco que formalmente no está autorizado para uso intraocular, por lo que habría que solicitar individualmente para cada paciente el uso compasivo, lo que es difícilmente viable. Además al tratarse de un fármaco 
genérico y barato los laboratorios en principio no están interesados en realizar los complejos trámites necesarios para lograr la autorización para uso intraocular.

Es importante informar a los gestores de nuestros hospitales y sistemas sanitarios de una novedad científica de la trascendencia de los resultados del ESCRS Endophthalmitis Study, para que se vean obligados a tomar las medidas que nos permitan aplicarla en el más breve plazo de tiempo posible en la práctica totalidad de los pacientes que se operen de cataratas. La seguridad de nuestros pacientes nos lo demanda y nuestra profesionalidad como cirujanos nos lo exige.

\section{BIBLIOGRAFÍA}

1. Alio JL, Muñoz G. Infectious endophthalmitis. In: BenEzra D. Ocular Inflammation: basic and clinical concepts. London: Martin Dunitz; 1999; 275-296.

2. Ciulla TA, Starr MB, Masket S. Bacterial endophthalmitis prophylaxis for cataract surgery: an evidence-based update. Ophthalmology 2002; 109: 13-24.

3. Barry P, Behrens-Baumann W, Pleyer U, Seal D. ESCRS guidelines on prevention, investigation and management of post-operative endophthalmitis. Dublin: European Society of Cataract and Refractive Surgeons; 2005.

4. Barry P, Seal DV, Gettinby G, Lees F, Peterson M, Revie $C W$, et al. ESCRS study of prophylaxis of postoperative endophthalmitis after cataract surgery: Preliminary report of principal results from a European multicenter study. J Cataract Refract Surg 2006; 32: 407-410. 